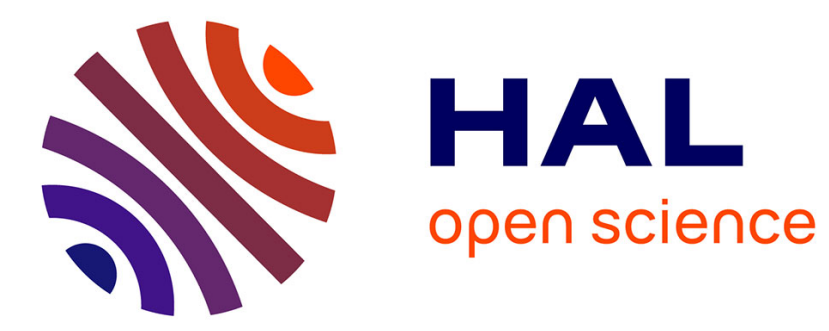

\title{
GPR40 mediates potential positive effects of a saturated fatty acid enriched diet on bone
}

Claire Philippe, Fabien Wauquier, Jean-Francois Landrier, Lauriane Bonnet, Elisabeth Miot-Noirault, Gaël Y. Rochefort, Jérémy Sadoine, Mohamed Asrih, François R. Jornayvaz, Annick Bernalier, et al.

\section{To cite this version:}

Claire Philippe, Fabien Wauquier, Jean-Francois Landrier, Lauriane Bonnet, Elisabeth Miot-Noirault, et al.. GPR40 mediates potential positive effects of a saturated fatty acid enriched diet on bone. Molecular Nutrition and Food Research, 2017, 61 (2), pp.1600219. 10.1002/mnfr.201600219 . hal01506660

\section{HAL Id: hal-01506660 \\ https://hal.science/hal-01506660}

Submitted on 12 Apr 2017

HAL is a multi-disciplinary open access archive for the deposit and dissemination of scientific research documents, whether they are published or not. The documents may come from teaching and research institutions in France or abroad, or from public or private research centers.
L'archive ouverte pluridisciplinaire HAL, est destinée au dépôt et à la diffusion de documents scientifiques de niveau recherche, publiés ou non, émanant des établissements d'enseignement et de recherche français ou étrangers, des laboratoires publics ou privés. 


\title{
GPR40 mediates potential positive effects of a saturated fatty acid enriched diet on bone
}

\author{
Claire Philippe ${ }^{1,2,3}$, Fabien Wauquier ${ }^{1,2,3}$, Jean-François Landrier ${ }^{4,5}$, Lauriane Bonnet ${ }^{4,5}$, \\ Elisabeth Miot-Noirault2,6, Gaël Y. Rochefort ${ }^{7}$, Jérémy Sadoine ${ }^{7}$, Mohamed Asrih ${ }^{8}$, \\ François R. Jornayvaz ${ }^{8}$, Annick Bernalier ${ }^{9}$, Véronique Coxam ${ }^{1,2,3}$ and Yohann Wittrant ${ }^{1,2,3}$ \\ ${ }^{1}$ INRA, UMR 1019, UNH, CRNH Auvergne, Clermont-Ferrand, France \\ ${ }^{2}$ Clermont Université, Université d'Auvergne, Unité de Nutrition Humaine, Clermont-Ferrand, France \\ ${ }^{3}$ Equipe Alimentation, Squelette et Métabolismes, Unité de Nutrition Humaine, Centre de Recherche INRA \\ Auvergne Rhône Alpes, Site de Theix, 63122 Saint Genés Champanelle, France \\ ${ }^{4}$ INRA, UMR1260, Nutriments Lipidiques et Prévention des Maladies Métaboliques, Marseille, France \\ ${ }^{5}$ Faculté de Médecine, Université de la Méditerranée Aix-Marseille 1 et 2, Marseille, France \\ ${ }^{6}$ INSERM, UMR990, IMTV, Clermont-Ferrand, France \\ ${ }^{7}$ EA 2496 Pathologie, Imagerie et Biothérapies Orofaciales, UFR Odontologie, Université Paris Descartes and PIPA, \\ PRES Sorbonne Paris Cité, Montrouge, France \\ ${ }^{8}$ Service d'Endocrinologie, Diabétologie et Métabolisme, Centre Hospitalier Universitaire Vaudois, Lausanne, \\ Switzerland \\ ${ }^{9}$ INRA UR454, Unité de Microbiologie, Clermont-Ferrand, France
}

Scope: The stimulation of the free fatty acid receptor G-protein coupled receptor (GPR) 40 by GW9508 prevents bone loss by inhibiting osteoclast activity, both in vitro and in vivo. Here, we questioned whether the stimulation of the GPR40 receptor by dietary fatty acids may lead to the same beneficial effect on bone.

Methods and results: We investigated (i) the impact of a fatty acid enriched diet (high-fat diet [HFD]) on bone health in C57/BL6 female mice depending on (ii) the estrogen status (ovariectomy) and (iii) the genotype (GPR40 $0^{+/+}$or GPR $40^{-/-}$). Bone mineral density (BMD), body composition, weight, inflammation and bone remodeling parameters were monitored. HFD decreased BMD in HFD-SH-GPR40 $0^{+/+}$mice but OVX failed to further impact BMD in HFD-OVX-GPR40 ${ }^{+/+}$mice, while additional bone loss was observed in HFD-OVX-GPR40-/animals. These data suggest that when stimulated by fatty acid enriched diets GPR40 contributes to counteract ovariectomy-induced bone alteration. The sparing effect is supported by the modulation of both the osteoprotegerin/receptor activator of nuclear factor kappa-B ligand (OPG/RANKL) ratio in blood stream and the expression level of inflammatory markers in adipose tissues. Bone preservation by GPR40 stimulation is dependent on the presence of long-chain saturated fatty acids.

Conclusion: GPR40 contributes to counter ovariectomy-induced bone loss in a context of saturated fatty acid enrichment.

Keywords:

Free fatty acid receptor / GPR40 / High-fat diet / Nutrition / Osteoporosis

Additional supporting information may be found in the online version of this article at the publisher's web-site
Received: March 9, 2016

Revised: July 29, 2016

Accepted: September 2, 2016
Correspondence: Dr. Yohann Wittrant

E-mail: yohann.wittrant@clermont.inra.fr

Abbreviations: ANOVA, analysis of variance; BMD, bone mineral density; GPR, G-protein coupled receptor; HFD, high-fat diet;
MCP-1, monocyte chemoattractant protein 1; OPG, osteoprotegerin; RANKL, receptor activator of nuclear factor kappa-B ligand Colour Online: See the article online to view Fig. 1 in colour. 


\section{Introduction}

A growing body of data has revealed complex relationships between dietary lipids and the skeleton [1]. Depending on the type of fatty acids, the biological activity on bone may differ. Literature has mainly evidenced that high-fat diets (HFDs) negatively impact bone health. However, most of the studies have focused their investigations on hyper caloric diets enriched with saturated fatty acids in healthy groups without asking whether a beneficial effect could exist under certain circumstances. Regarding the unsaturated fatty acid family, the $\omega-6$ family has been shown to enhance osteoporosis establishment while $\omega-3$ fatty acids seem to preserve bone tissues [2-5]. These seemingly conflicting results have raised the idea that in some ways the modulation of the lipid intakes may represent a preventive opportunity for the management of bone complications. However, mechanisms of action are poorly understood and further investigations are required to develop innovative strategies regarding fat involvement in osteoporosis management.

About a decade ago, several groups demonstrated that the G-protein coupled receptor (GPR) 40 was able to interact with medium- to long-chain fatty acids and to transduce a specific signal across the cell membrane [6-11]. The role of GPR40 (also known as Free Fatty Acid Receptor-1) was mainly examined in beta-cells for its involvement in insulin secretion [12-14]. Later, GPR40 roles were discovered in taste buds [15], enteroendocrine cells [16], and in the brain [17, 18].

Recently, we demonstrated in vivo and in vitro the implication of this receptor in bone homeostasis [19-22]. GPR40-/mice were characterized by an osteopenic/osteoporotic phenotype when compared to wild-type (WT) littermates. In addition, phenotype onset was prevented in WT ovariectomized mice when a GPR40 synthetic agonist, GW9508, was given orally. We further demonstrated that prevention by GW9508 was driven by an inhibition of osteoclastogenesis in a GPR40 dependent way. This synthetic agonist was used to decipher the role of GPR40 and to avoid confounding parameters. However, since free fatty acids are natural ligands for GPR40, we further questioned the relevance of this receptor in an integrative approach investigating whether this fatty acid receptor may represent an innovative opportunity in the design of nutritional and therapeutic strategies to prevent bone loss in an ageing population.

\section{Materials and methods}

\subsection{Ethics}

All animal procedures were approved by the institution's animal welfare committee (Comité d'Ethique en Matière d'Expérimentation Animale Auvergne: CEMEAA) and were conducted in accordance with the European guidelines for the care and use of laboratory animals (CE 80-12). Animals were housed in the animal facility of the INRA Research for Human Nutrition (Agreement $\mathrm{N}^{\circ}$ : C6334514). Throughout the study, animals were housed in a controlled environment characterized by a $12: 12 \mathrm{~h}$ light-dark cycle, $20-22^{\circ} \mathrm{C}, 50-60 \%$ relative humidity. Mice were kept one per plastic cage with free access to water. At the end of the protocol, blood was withdrawn from anesthetized animals. Then, animals were sacrificed by cervical dislocation and tissues were harvested, frozen, and stored prior to investigation.

\subsection{Genotype}

GPR40-1- mice were obtained from AMGEN Inc. As described by Latour et al. [19], GPR40 ${ }^{-1-}$ mice on a mixed C57BL/6/129 background were generated by homologous recombination in embryonic stem cells at Lexicon Genetics (The Woodlands, TX, USA). Exon 2 of the GPR40 gene was replaced with a LacZ gene. The mice were backcrossed onto the C57BL/6 strain over nine generations. Pups were screened by PCR performed on genomic DNA. WT littermates were used as controls.

\subsection{Experimental design}

In order to accustom the mice to the texture, animals were provided with free access to a standard growth powdered diet during an acclimatization period of 3 weeks from weaning (weeks 4-7). On week 7, mice were randomly divided into 16 groups ( $n=12$, individual cage), depending on the diet (six different diets), the type of surgery (SH or OVX) and the genotype (GPR40 $0^{+/+}$or GPR40-/-; Tables 1 and 2). From this point, mice were provided with their specific diet. On week 9 , mice were sham-operated or ovariectomized to induce bone loss. Diets were delivered ad libitum for a total of 7 weeks including 5 weeks postsurgery (Fig. $1 \mathrm{~A}$ and B). Briefly, every $48 \mathrm{~h}$, each mouse received exactly $10 \mathrm{~g}$ of the diet in a small bowl (Fig. 1) to cover their needs (about 3-4 g per day; Fig. 4B). Food was changed every $48 \mathrm{~h}$ to minimize fatty acid oxidation. Once a week, the leftover food was weighted to evaluate the consumption of each mouse.

\subsection{Ovariectomized mice}

Mice were either sham-operated to mimic the side effects of the surgery or ovariectomized to induce an estrogen deprivation and a subsequent bone loss.

\subsection{Diets}

Diets were purchased from our experimental facility dedicated to the conception of animal diets (INRA UE0300, UPAE Unité de Préparation des Aliments Expérimentaux, Jouy-enJosas, France). Compositions are summarized in Table 2. Diets were provided to the mice as powders and not as croquettes to avoid fatty acid heating and alteration during the croquettes' production process. The fatty acid enrichment in 
Table 1. Distribution of the groups

\begin{tabular}{|c|c|c|c|c|c|c|c|c|c|c|c|c|c|c|c|c|}
\hline \multirow{2}{*}{$\begin{array}{l}\text { Diets } \\
\text { Surgery }\end{array}$} & \multicolumn{4}{|c|}{ Control } & \multicolumn{4}{|c|}{ HFD } & \multirow{2}{*}{\multicolumn{2}{|c|}{$\begin{array}{l}\text { HFD } \\
\text { saturated } \\
\text { OVX }\end{array}$}} & \multirow{2}{*}{\multicolumn{2}{|c|}{$\begin{array}{l}\text { HFD } \omega-6 \\
\text { OVX }\end{array}$}} & \multirow{2}{*}{\multicolumn{2}{|c|}{$\begin{array}{l}\text { HFD } \omega-9 \\
\text { OVX }\end{array}$}} & \multirow{2}{*}{\multicolumn{2}{|c|}{$\begin{array}{l}\text { HFD } \omega-3 \\
\text { OVX }\end{array}$}} \\
\hline & $\mathrm{SH}$ & & ovX & & $\mathrm{SH}$ & & OVX & & & & & & & & & \\
\hline Genotype & WT & $\mathrm{KO}$ & WT & KO & WT & $\mathrm{KO}$ & WT & $\mathrm{KO}$ & WT & $\mathrm{KO}$ & WT & KO & WT & $\mathrm{KO}$ & WT & $\mathrm{KO}$ \\
\hline
\end{tabular}

HFDs was obtained by a modulation of the corn starch content and in these cases, $42.18 \%$ of the calories were related to the fat content and $46.54 \%$ from the carbohydrate content. The total amount of calories was higher in the fatty acid enriched groups than in the control ones $(464 \mathrm{kcal} / 100 \mathrm{~g}$ of diet versus $373 \mathrm{kcal} / 100 \mathrm{~g}$ of diet, respectively). The groups with fatty acid enrichment were isocaloric. This parameter was taken into account to allow group comparisons and to avoid any bias in the conclusions. The fatty acid profile of the HFD was designed to meet French dietary guidelines in terms of fatty acid ratios and set a reference point for the fatty acid content (Table 3). To test whether one fatty acid class may better activate GPR40 than another, selective enrichments of the diet were designed to produce saturated, omega-3, -6, and -9 HFDs (Table 2).

\subsection{Bone mineral density analysis}

After removing soft tissues, left femurs were placed in PBS with $10 \%$ formaldehyde at $4^{\circ} \mathrm{C}$ for 1 week. Bone mineral density (BMD) was measured using an eXplore CT 120 scanner
(GE Healthcare, Canada). Acquisitions were performed with $\mathrm{X}$-ray tube settings at $100 \mathrm{kV}$ and $50 \mathrm{~mA}$. We limited our investigation to the trabecular region of the distal metaphysis of the left femurs. ROI was set at $2000 \mu \mathrm{m}$ height. Measurements started $300 \mu \mathrm{m}$ in the proximal direction from the growth plate.

\subsection{Body mass and composition}

Mice were weighed every week throughout the experimental period and subjected to body composition analysis at the beginning and at the end of the protocol using QMR EchoMRI- 900 system. Whole body fat and lean (excluding bone mass) mass were measured in living animals with no need of sedation.

\subsection{Tissue weight analysis}

Mice total body weight was measured weekly throughout the study. Spleen and uterus were collected from mice and weighed immediately after sacrifice.

Table 2. Composition of HFDs

\begin{tabular}{|c|c|c|c|c|c|c|}
\hline Diets & Control & HFD & Saturated HFD & Omega-6 HFD & Omega-3 HFD & Omega-9 HFD \\
\hline Ingredients & $\%$ & $\%$ & $\%$ & $\%$ & $\%$ & $\%$ \\
\hline Casein & 14.00 & 14.00 & 14.00 & 14.00 & 14.00 & 14.00 \\
\hline Sucrose & 10.00 & 10.00 & 10.00 & 10.00 & 10.00 & 10.00 \\
\hline Dextrin (maltodextrin) & 15.50 & 15.50 & 15.50 & 15.50 & 15.50 & 15.50 \\
\hline Cellulose & 5.00 & 5.00 & 5.00 & 5.00 & 5.00 & 5.00 \\
\hline Corn oil & 7.00 & - & 4.00 & 4.00 & 4.00 & 4.00 \\
\hline Rapeseed oil & - & 6.72 & - & - & - & - \\
\hline Sunflower oil & - & - & - & 20.00 & - & - \\
\hline $\begin{array}{l}\text { Fish oil concentrated 22/60 } \\
\text { TG (EPA/DHA) }\end{array}$ & - & 0.48 & - & - & - & - \\
\hline $\begin{array}{l}\text { Fish oil Omegavie DHA } 70 \\
\text { TG QS ICE }\end{array}$ & - & - & - & - & 20.00 & - \\
\hline Olive oil & - & - & - & - & - & 20.00 \\
\hline Lard & - & 16.80 & 20.00 & - & - & - \\
\hline I-cystine & 0.18 & 0.18 & 0.18 & 0.18 & 0.18 & 0.18 \\
\hline Choline bitartrate & 0.25 & 0.25 & 0.25 & 0.25 & 0.25 & 0.25 \\
\hline $\begin{array}{l}\text { Mineral mix (AIN-93M) Ca } \\
\text { normal }(0.5 \% \text { per kg of } \\
\text { diet) }\end{array}$ & 3.50 & 3.50 & 3.50 & 3.50 & 3.50 & 3.50 \\
\hline $\begin{array}{l}\text { Vitamins (AIN-93M) normal } \\
\text { vitD (1000 Ul diet) }\end{array}$ & 1.00 & 1.00 & 1.00 & 1.00 & 1.00 & 1.00 \\
\hline$t$-Butyl-hydroxyquinon & 0.008 & 0.008 & 0.008 & 0.008 & 0.008 & 0.008 \\
\hline Corn starch (by difference) & 43.56 & 26.56 & 26.56 & 26.56 & 26.56 & 26.56 \\
\hline Verification & 100 & 100 & 100 & 100 & 100 & 100 \\
\hline
\end{tabular}




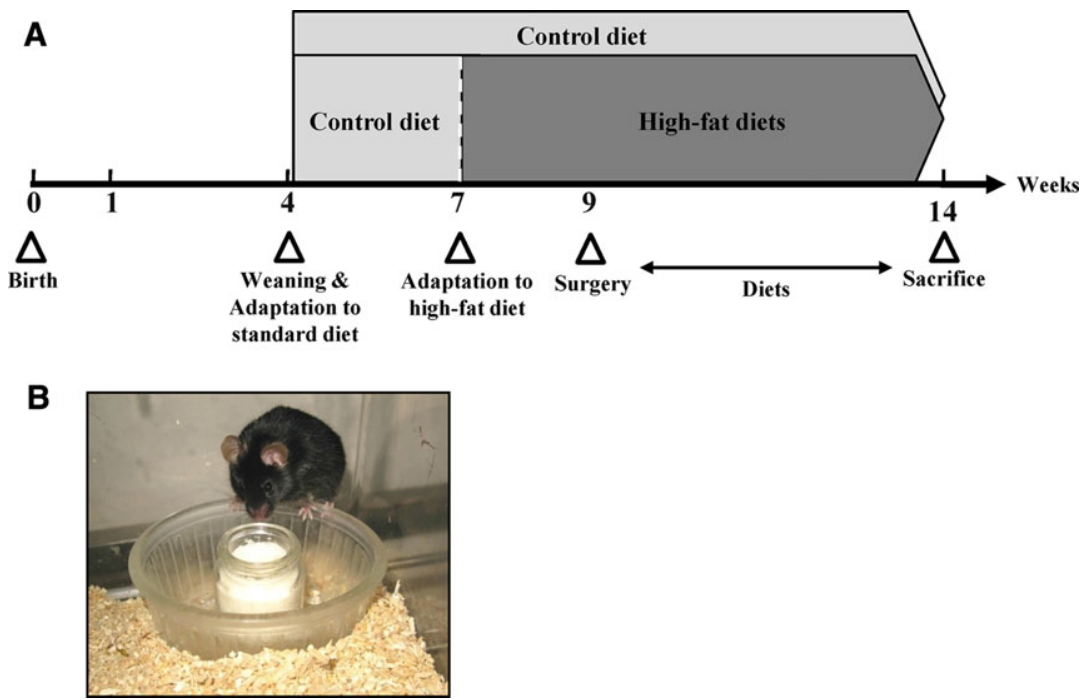

Figure 1. Scheme of experimental protocol design (A) and presentation of the food distribution mode (B). Acclimatization period (weeks 4-7); On week 7, mice were randomized into 16 groups ( $n=12$, individual cage) and provided with their specific diet (six different diets; two different genotypes; see Tables 1 and 2); On week 9, mice were ovariectmized or shamoperated to induce bone loss. Diets were delivered ad libitum for a total of 7 weeks including 5 weeks postsurgery.

Table 3. Validation of fatty acid composition of diets

\begin{tabular}{llc}
\hline Fatty acid & Control (\%) & HFD (\%) \\
\hline C12:0 & - & 0.18 \\
C14:0 & 0.24 & 1.95 \\
C16:0 & 15.29 & 25.71 \\
C16:1 $n-9$ & - & 0.32 \\
C16:1 $n-7$ & - & 2.41 \\
C17:0 & - & 0.23 \\
C17:1 & - & 0.2 \\
C18:0 & 1.54 & 9.12 \\
C18:1 $n-9$ & 27.07 & 36.51 \\
C18:1 $n-7$ & - & 5.98 \\
C18:2 $n-6$ cis & 55.04 & 12.91 \\
C20:1 $n-9$ & - & 0.34 \\
C18:3 $n-3$ & 0.82 & 3.07 \\
C20:5 $n-3$ & - & 0.6 \\
C22:6 $n-3$ & - & 0.48 \\
Verification & $100 \%$ & $99.53 \%$ \\
\hline
\end{tabular}

\subsection{Biochemical parameters}

Blood samples from 14-week-old mice were collected in tubes for serum chemistry, and centrifuged. Serum was isolated, aliquoted, and stored at $-80^{\circ} \mathrm{C}$. Osteoprotegerin (OPG), receptor activator of nuclear factor kappa-B ligand (RANKL), and monocyte chemoattractant protein 1 (MCP-1) were measured by Quantikine ELISA for mouse (R\&D Systems Europe).

\subsection{Statistics}

The experimental procedure was conducted with a total of 12 mice per group. The 16 groups were processed at the same time but Ctrl and HFD groups (for a total of eight groups; see Table 1) were investigated first and were the only groups fully investigated for all parameters. Statistics were performed to either investigate the role of the genotype (GPR $40^{+/+}$versus GPR40 ${ }^{-1-}$ ), the role of the ovariectomy (Ctrl-SH versus CtrlOVX), the role of the diet (Ctrl-SH versus Ctrl-HFD), or the role of the diet when mice were ovariectomized (HFD-SH versus HFD-OVX). Then, the obtained data were analyzed via a multivariate analysis of variance (ANOVA) followed by a Tukey's test. Data are presented as mean \pm SD. (ExcelStat Pro software-Microsoft Office 2007.) Groups with significant differences $(p<0.05)$ are indicated with different letters or $(*)$.

\section{Results}

\subsection{Validation of the bone loss model}

To validate ovariectomy-induced oestrogen deficiency, mice uteri were weighed and checked for atrophy. As expected, uterus mass of the ovariectomized animals was significantly lower than those isolated from sham-operated females (Fig. 2). Consistently, BMD was significantly decreased in Ctrl-OVX-GPR40 ${ }^{+/+}$mice compared to Ctrl-SH-GPR40 ${ }^{+/+}$ (Fig. 3A). In addition, as previously described, BMD in GPR40 $^{-/-}$mice was significantly lower than in GPR40+/+ WT littermates (Fig. 3A), thus validating the consistency of both the OVX and the GPR40-1- mouse models, and allowing further investigation.

\subsection{GPR40 limits bone loss induced by ovariectomy upon HFD}

As shown in Fig. 3B, HFD-induced bone loss in HFD-SHGPR $40^{+/+}$mice but OVX failed to further impact BMD in HFD-OVX-GPR $40^{+/+}$mice. In contrast, the absence of GPR40 revealed an additional BMD decrease in HFD-OVXGPR40 $^{-1-}$ mice (Fig. 3C). These data suggest that, when stimulated by fatty acid enriched diets, GPR40 contributes to counteract ovariectomy-induced bone alteration. 

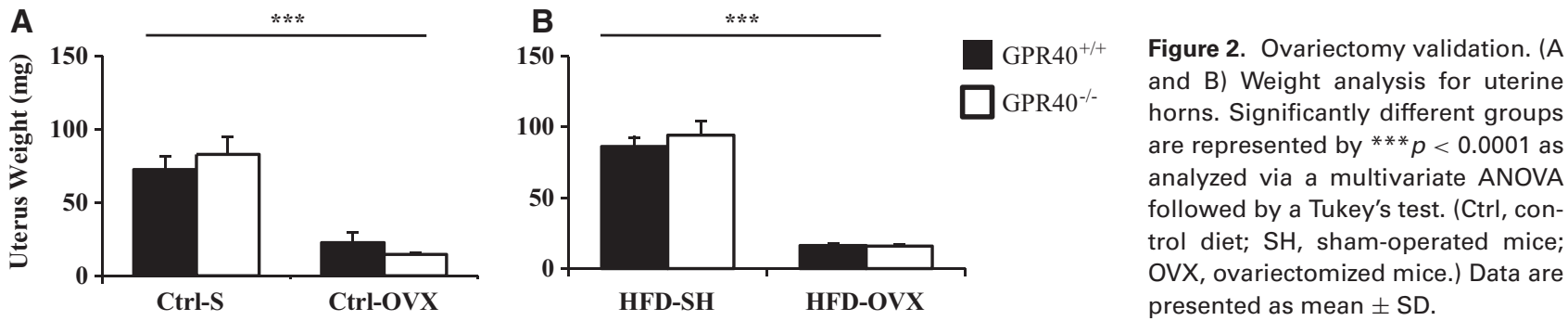

\subsection{The protective effect of GPR40 is not related to mechanical protection}

To ensure that GPR40 protective effects were not related to weight gain and subsequent mechanical loading due to an HFD, mice weight was monitored weekly throughout the experiment. Only ovariectomy significantly increased animals' weight, whereas diet or genotype had no, or little effect on weight gain, suggesting that the absence of further bone loss in HFD-OVX-GPR40 ${ }^{+/+}$is not related to a modulation of the mechanical loading (Fig. 4A).

\subsection{The absence of GPR40 leads to higher fat/lean mass ratio}

EchoMRI data reveal that ovariectomy exerted a significant influence on body composition pattern with a decreased lean mass and an increased fat mass (Fig. 4C, D, and E). HFD had no particular effect on body composition, except in the absence of GPR40. Indeed, HFD-SH-GPR40-/- mice showed a greater percentage of fat, while HFD failed to induce such a gain in HFD-SH-GPR40 ${ }^{+/+}$mice (Fig. 4D and E). This difference reveals that GPR40 may contribute to limit dietinduced fat gain and adipose tissue hypertrophy.

\subsection{HFD causes increased systemic inflammation}

To elucidate the role of HFD on bone behavior we questioned its impact on inflammatory status. Mice fed with the HFD exhibited both higher spleen weight and MCP-1 level in the serum ( $p<0.0264$ and $p<0.0001$, respectively) independently of the oestrogen status or genotype (Fig. 5A and $\mathrm{B}$, second panels). These results support a global negative impact of the HFD on inflammatory parameters that may contribute to explain, at least in part, the subsequent loss of BMD observed in HFD-SH mice. Ovariectomy or genotype had no significant impact on systemic inflammatory status.

\subsection{Inflammation in adipose tissue is increased by ovariectomy and enhanced in the absence of GPR40}

As aforementioned, ovariectomy did not significantly impact the systemic inflammatory status. However, locally, it increased the production of the proinflammatory cytokine MCP-1 by the inguinal adipose tissue (Fig. 5C, left and right panels). In contrast, the diet was ineffective. Regarding genotype influence, the absence of GPR40 mostly increased the production of TNF- $\alpha$. Interestingly, when mice were ovariectomized and fed an HFD, the absence of GPR40 led to a massive increase of both TNF- $\alpha$ and MCP-1 cytokines, supporting an anti-inflammatory role for GPR40 at the adipose tissue level.

\subsection{The absence of GPR40 leads to a greater production of RANKL}

The analysis of OPG and RANKL expression, two major cytokines involved in bone tissue homeostasis, reveals that BMD level parallels OPG/RANKL ratio. These data suggest a key role for this molecular cross-talk between osteoblasts and osteoclasts in mediating ovariectomy, diet, and genotype influences on BMD (Fig. 6C, all panels). Interestingly, while no or little impact on OPG was observed in the HFD-OVXGPR $40^{-1-}$ group, the absence of GPR40 led to a remarkably increased level of RANKL (Fig. 6A and C, right panels). This
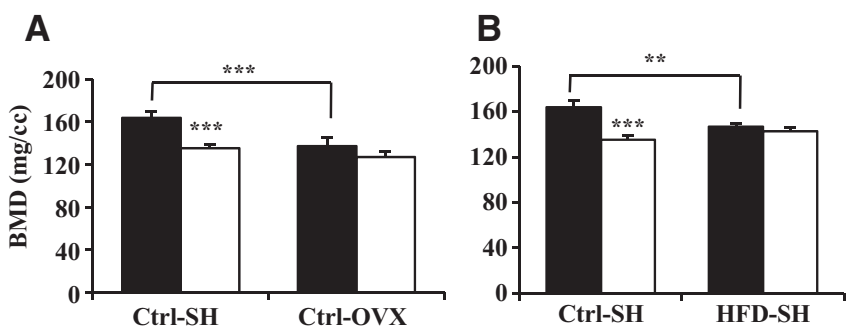

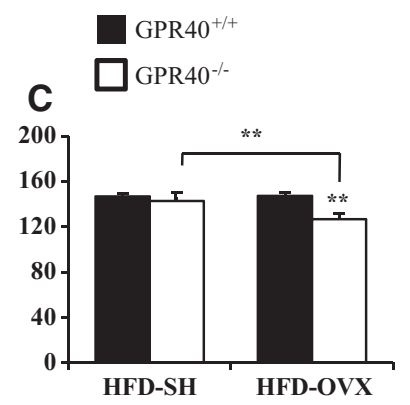

Figure 3. Bone parameters. (A and B) BMD. Significantly different groups are represented by ${ }^{* *} p<0.0001$ or ${ }^{* *} p<$ 0.01 as analyzed via a multivariate ANOVA followed by a Tukey's test. (Ctrl, control diet; $\mathrm{SH}$, sham-operated mice; OVX, ovariectomized mice.) Data are presented as mean \pm SD. 

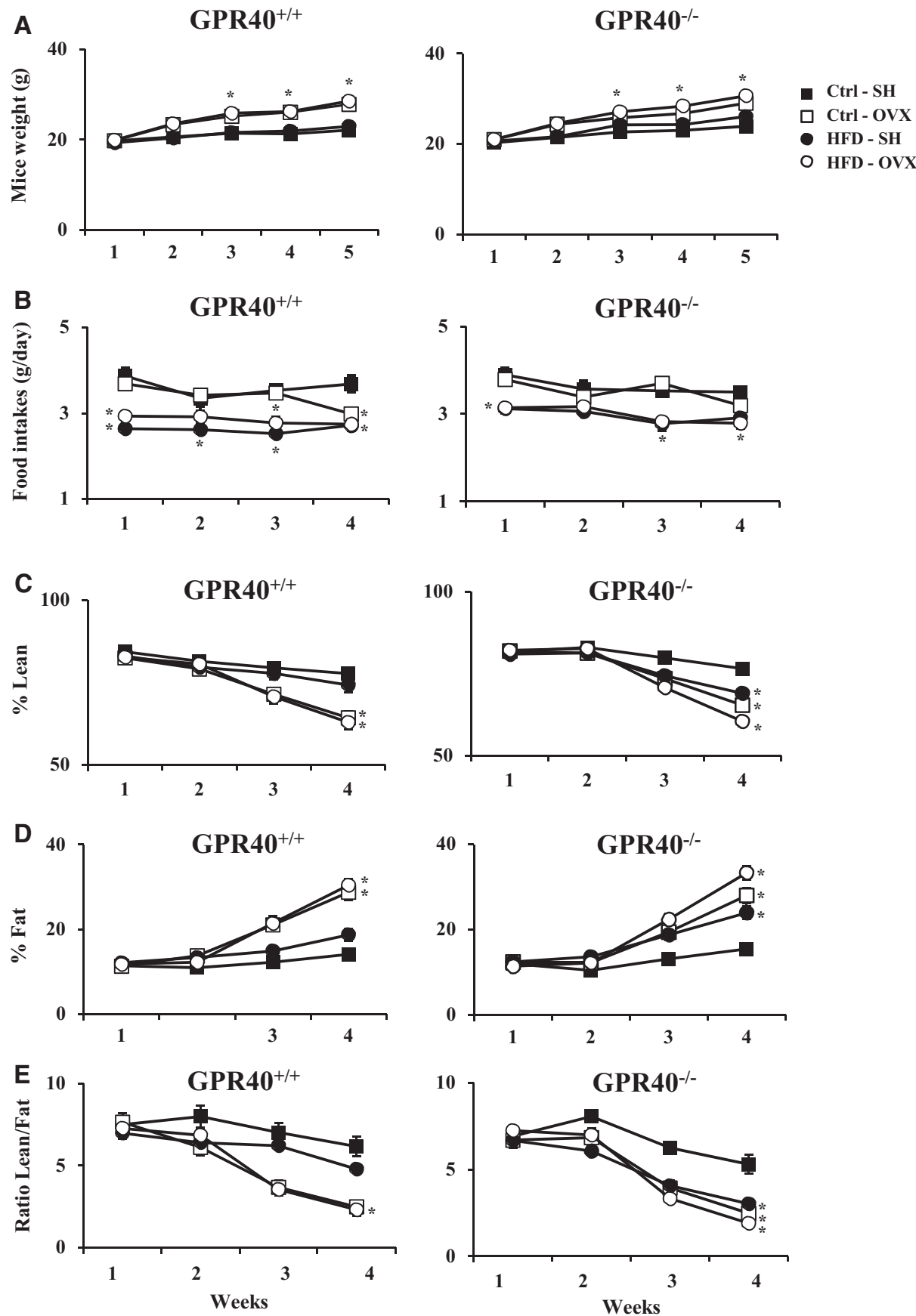

Figure 4. Weight, food intake, and body composition parameters. Total body weight gain over the complete study of GPR40+/+ and GPR4O-I- mice (A). Food intake over the complete study of $G P R 40^{+/+}$and GPR4O- 4 - mice (B). Percentage of $G P R 40^{+/+}$and $G P R 40^{-/-}$lean gain over the complete study $(C)$, percentage of $G P R 40^{+/+}$and $G P R 40^{-/-}$ fat gain over the complete study (D), and ratio of $G P R 40^{+/+}$and $G P R 40^{-/-}$ lean/fat over the complete study (E). Significantly different groups are represented by ${ }^{*} p<0.05 \mathrm{com}$ pared to control as analyzed via a multivariate ANOVA followed by a Tukey's test. (Ctrl, control diet; SH, sham-operated mice; OVX, ovariectomized mice.) Data are presented as mean $\pm \mathrm{SD}$. increase correlates with the observed alteration of bone and strongly supports that HFD no longer limits a greater bone resorbing cell differentiation in the absence of GPR40.

\subsection{GPR40 bone sparing effect may rely on stimulation by saturated fatty acids}

Since we demonstrated the role of GPR40 in mediating HFD positive influence in OVX-induced bone loss, we questioned the specificity on the receptor. The HFD combines different fatty acid groups. In order to decipher which one of these could be responsible for GPR40-related protection, fatty acid mixture composition was revised to allow diet enrichment either with saturated, $\omega-3, \omega-6$, or $\omega-9$ fatty acids. Only the diet rich in saturated fatty acid showed similar effects to the so-called HFD diet while diets rich in $\omega-3, \omega-6$, or $\omega-9$ failed to promote GPR40-related protection of bone tissue (Fig. 7). These data support a specificity for GPR40 toward saturated fatty acids that has never been reported before. 
A

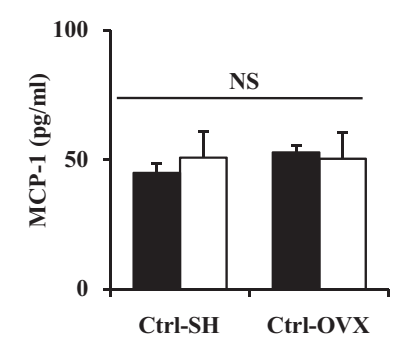

B
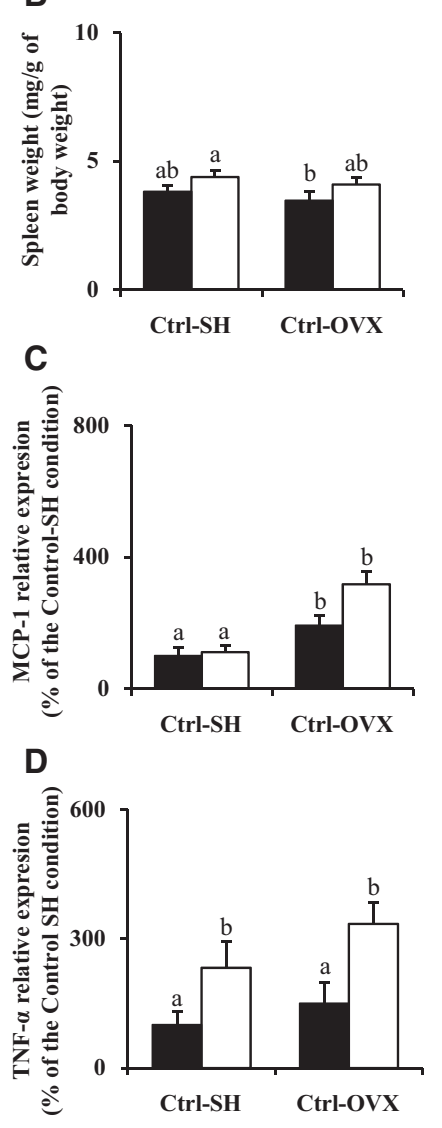
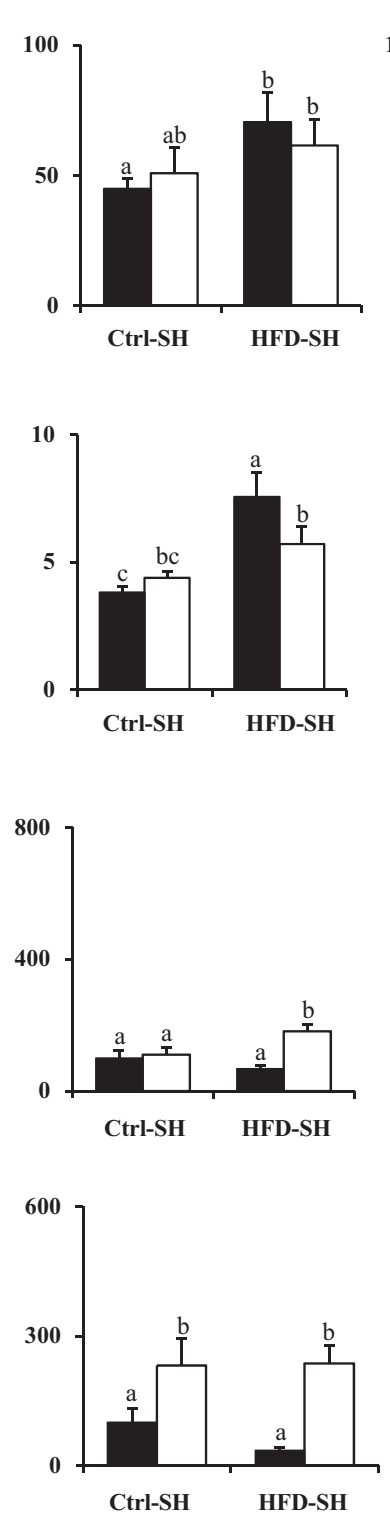
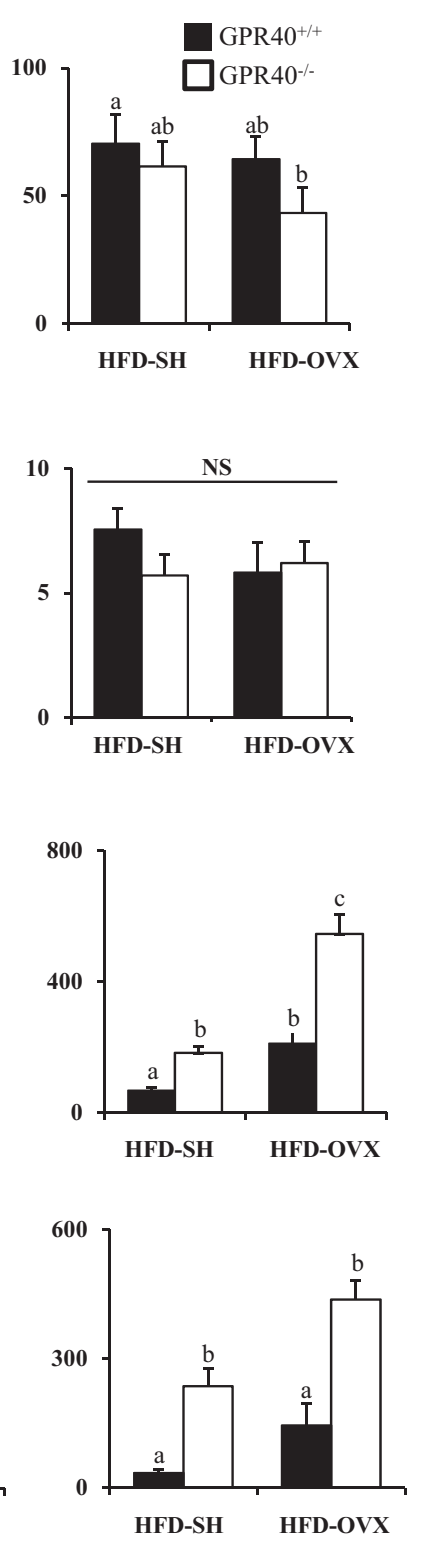

Figure 5. Inflammation parameters. (A) Monocyte chemotactic protein 1 (MCP-1) level analysis in blood samples. (B) Spleen weight measurement. (C) MCP1 mRNA relative expression in white adipose tissue. (D) TNF$\alpha$ mRNA relative expression in white adipose tissue. Significantly different groups are represented by different letters as analyzed via a multivariate ANOVA followed by a Tukey's test, $p<$ 0.05. (Ctrl, control diet; SH, shamoperated mice; OVX, ovariectomized mice.) Data are presented as mean \pm SD.

\section{Discussion/conclusion}

In this study, we demonstrated for the first time that GPR40 contributes to limit ovariectomy-induced bone loss when mice were fed an HFD. Limitation of bone loss in this model was associated with both a restrained production of proinflammatory cytokines by the white adipose tissue and a controlled level of RANKL. GPR40-related protection of bone tissue was dependent on the presence of saturated fatty acids. These results are consistent with previous published data obtained with the synthetic agonist GW9508.

We also confirmed that mice lacking GPR40 exhibited osteoporotic features [19]. As expected, oestrogen deficiency following ovariectomy was confirmed by uterine horns atrophy and led to bone loss independently of the diet or the

genotype $[23,24]$. Then, we provided evidence that HFD decreased BMD in HFD-SH-GPR $40^{+/+}$mice. This deleterious impact of the diet on bone parallels previous studies from Le's and Faria's groups showing that bone loss upon HFD was associated with an unbalanced osteoblast/osteoclast coupling and an increased of inflammatory status $[25,26]$. In our hands, HFD increased MCP-1 level and spleen weight. Alteration of the OPG/RANKL ratio by the diet was also observed. Besides, bone loss observed in HFD-SH-GPR40+/+ mice occurred in the absence of weight gain supporting a metabolic deleterious effect of the diet uncovered by the absence of mechanical loading [27].

Interestingly, ovariectomy failed to further impact BMD in HFD-OVX-GPR $40^{+/+}$mice, while additional bone loss was observed in HFD-OVX-GPR $40^{-/-}$animals. These data 
A

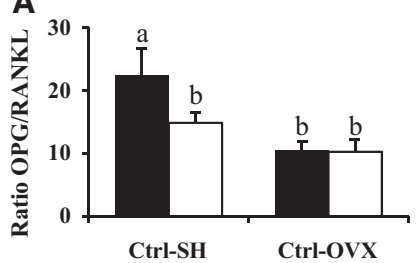

B
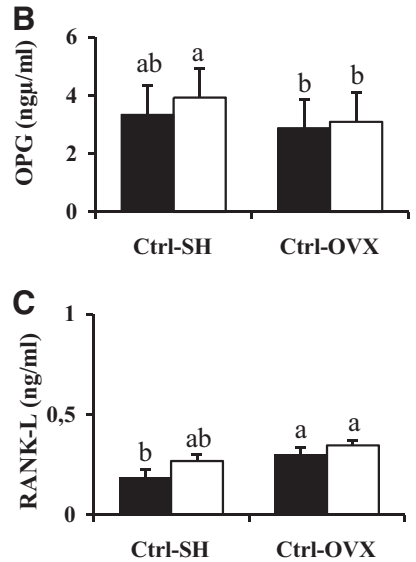
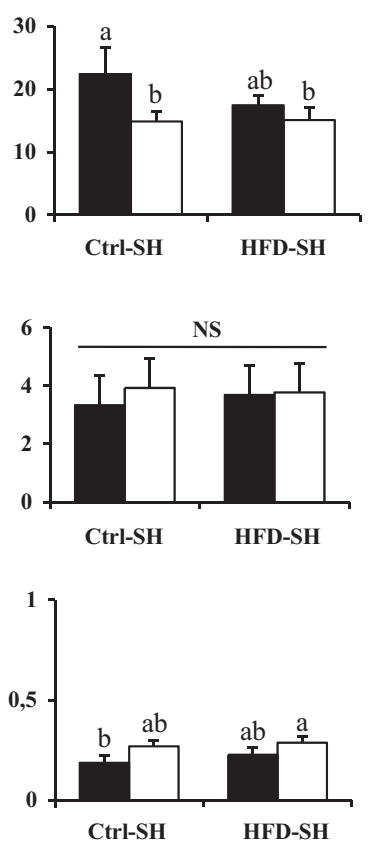

$\mathrm{GPR} 40^{+/-}$

$\square$ GPR $40^{-/-}$
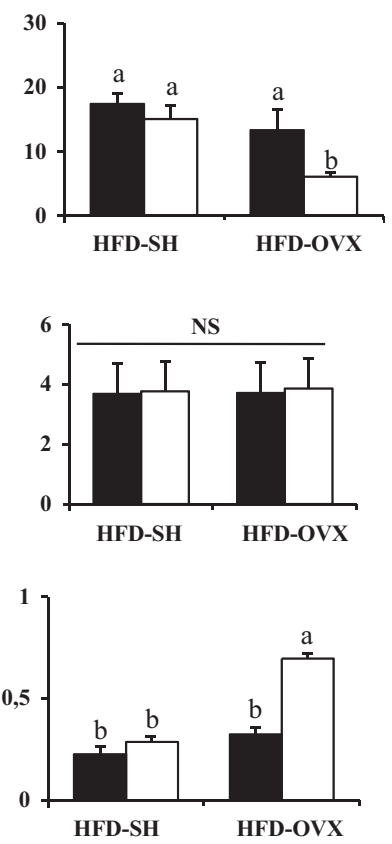

Figure 6. OPG and RANKL serum levels. (A and B) OPG and RANKL levels in blood samples. (C) OPG/RANKL levels ratio. Significant different groups are represented by different letters as analyzed via a multivariate ANOVA followed by a Tukey's test, $p<0.05$. (Ctrl, control diet; $\mathrm{SH}$, sham-operated mice; OVX, ovariectomized mice.) Data are presented as mean $\pm \mathrm{SD}$. support a positive role for GPR40 in bone sparing effect and strongly suggest that, when stimulated by fatty acid enriched diets, GPR40 contributes to counteract ovariectomy-induced bone alteration.

Ovariectomy-induced bone loss mainly relies on a rapid increase of osteoclast activity [28]. Besides, both osteoclast activity and differentiation are stimulated by proinflammatory conditions [29]. The presence or the absence of GPR40 did not significantly impact circulating level of MCP-1 or spleen weight. Therefore, while inflammation induced by HFD may account for the bone loss observed, the limitation of the OVXinduced bone loss by GPR40 cannot be explained by a modulation of the systemic inflammatory status. At the tissue level, ovariectomy increased TNF- $\alpha$ and MCP-1 expression by the inguinal white adipose tissue. This increase was enhanced by the absence of GPR40 and further strengthened when combined with HFD in the HFD-OVX-GPR40-/- group. MCP1 released by adipocytes contributes to recruit macrophages that enhance a local inflammatory vicious cycle. Interestingly, this local macrophage recruitment may involve specific populations such as Ly6C monocytes that have the ability to migrate from bone marrow to inflammation sites, get activated and then return to bone marrow where they may contribute to initiate or enhance an inflammatory context with deleterious effect on bone health [30]. This concept is of particular interest and may explain, at least in part, the seemingly conflicting

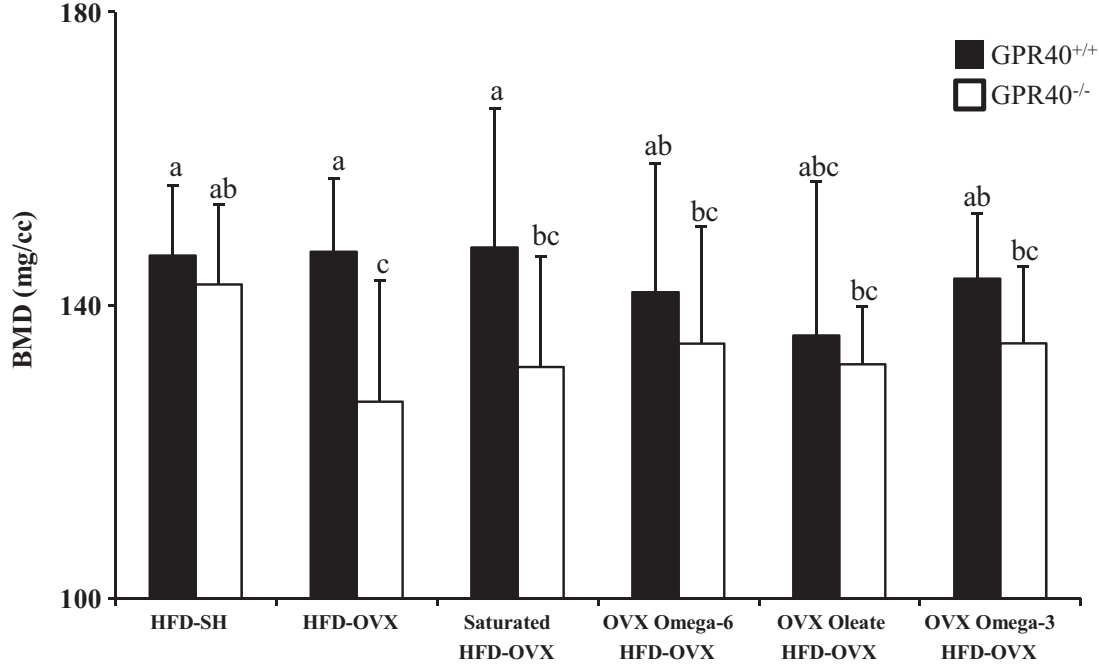

Figure 7. BMD of WT and knock-out GPR40 mice depending on fatty acid class-enriched diets. Significant different groups are represented by different letters as analyzed via a multivariate ANOVA followed by a Tukey's test. Data are presented as mean \pm SD. 


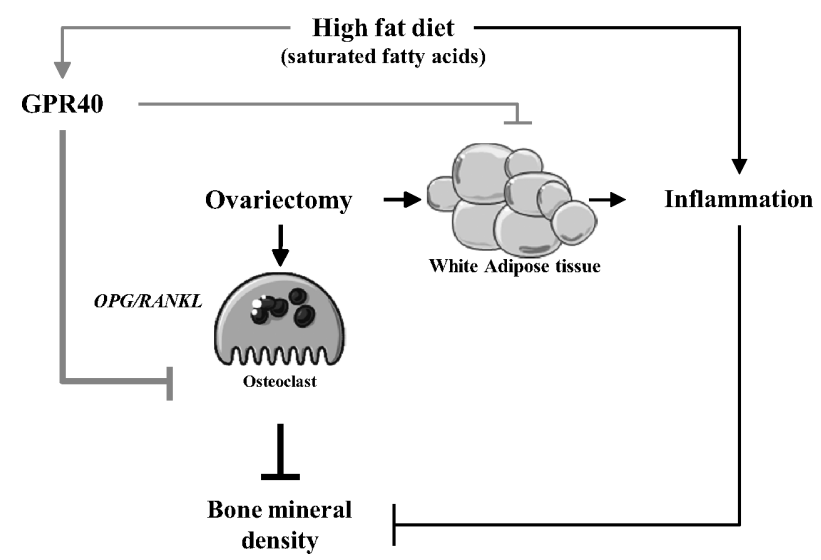

Figure 8. Conclusion GPR40 contributes to counteract ovariectomy-induced bone alteration in the presence of fatty acid enriched diets. The sparing effect is supported by the modulation of the OPG/RANKL ratio in blood stream and the expression level of inflammatory markers in local adipose tissues. The importance of GPR40 in osteoclastogenesis has been previously described.

results between the systemic and local level of MCP-1 in line with the role of GPR40 in both adipose and bone tissues [30]. Furthermore, these results parallel the fat gain observed in the OVX mice and strongly support that OVX and diet act in concert to increase the local production of proinflammatory cytokines by the adipose tissue while the presence of GPR40 limits it.

To further decipher the mechanism of action, the modulation of the OPG/RANKL ratio was assessed. Consistently, OPG/RANKL ratio was significantly decreased in HFD-OVXGPR40 ${ }^{-1-}$. This unbalanced ratio was driven by an increase in RANKL production while OPG was unaffected. According to both, the role of RANKL in osteoclast differentiation and our previous published data [19] regarding the bone phenotype of the GPR $40^{-1-}$ mice, the additional decrease of bone mass observed in HFD-OVX-GPR40 ${ }^{-1-}$ animals may originate from an uncovered inhibition of bone resorption mediated by fatty acids and GPR40 interaction. Although Gao et al. [31] recently demonstrated that GPR40 may promote osteogenic differentiation through Wnt/ $\beta$-catenin pathway, in our hands osteoblasts were only weakly affected in vivo by GPR40 [20]. This further supports the paramount role of the osteoclast in this story [20].

To sum up the results, our data suggest that a diet enriched with saturated fatty acids leads to decreased BMD but in a limited way due to GPR40 stimulation by fatty acids. The positive role of GPR40 in both adipose and bone tissues contributes to counter ovariectomy-induced bone loss (Fig. 8). Regarding fatty acid specificity, GPR40 was first described as a fatty acid receptor binding medium- to long-chain fatty acids independently of their degree of saturation $[6,7,13]$. Here, we demonstrate that GPR40-related bone protection seems to be preferentially mediated by saturated fatty acids. Despite this contrast with the literature, it is worth noting that just like
GPR40, GPR120 was first described as a receptor for mediumto long-chain fatty acids lacking specificity before Oh's group evidenced it as a DHA sensor [32]. Besides, our data parallel those from Cornish's group [33]. They demonstrated that saturated fatty acids (C14:0-C18:0) inhibited osteoclastogenesis in bone marrow cultures and RAW264.7 cells expressing GPR40. Still, consistent with our results regarding the influence of diets either enriched in $\omega-3, \omega-6$, or $\omega-9$, they found that the introduction of double bonds abrogated the inhibition of osteoclastogenesis with comparable low activity between $\omega-3$ and $\omega-6$ fatty acids.

In a context of increasing prevalence of obesity in occidental countries, it appears difficult from a nutritional view point to encourage long-chain saturated fat intake. Therefore, even if stimulation of the GPR40 receptor by saturated fatty acids contributes to limit excessive bone loss, this study may remain of mechanistic interest and our results rather support the relevance of pharmacologic approaches. Nevertheless, it is worth noting that GPR40 also binds medium-chain saturated fatty acids, such as myristic acid, that have been shown to limit the prevalence of metabolic complication $[34,35]$. The relevance of such a class of lipids regarding bone health prevention remains to be investigated.

C.P., F.W., V.C., and Y.W. designed the study and wrote the manuscript. G.Y.R., J.S., and E.M.-N. were in charge of the bone investigation. J.-F.L. and L.B. were in charge of the adipose tissue investigation. M.A. and F.R.J. were in charge of the insulin sensitivity. A.B. was in charge of the microbiota investigation.

The authors would like to thank all the people who contributed to the ovariectomy procedures, the diet delivery, and the tissue sampling. They also thank Vincent Poitout and AMGEN for providing them the GPR40 mouse strain. They also express gratitude to Lisa Nucke for English grammar and syntax improvement.

The authors have declared no conflict of interest.

\section{References}

[1] Wauquier, F., Leotoing, L., Philippe, C., Spilmont, M. et al., Pros and cons of fatty acids in bone biology. Prog. Lipid Res. 2015, 58, 121-145.

[2] Corwin, R. L., Effects of dietary fats on bone health in advanced age. Prostaglandins Leukot. Essent. Fatty Acids 2003, 68, 379-386.

[3] Calder, P. C., $n$-3 Polyunsaturated fatty acids, inflammation, and inflammatory diseases. Am. J. Clin. Nutr. 2006, 83, 1505S-1519S.

[4] Ono, K., Kaneko, H., Choudhary, S., Pilbeam, C. C. et al., Biphasic effect of prostaglandin E2 on osteoclast formation in spleen cell cultures: role of the EP2 receptor. J. Bone Miner. Res. 2005, 20, 23-29.

[5] Tsutsumi, R., Xie, C., Wei, X., Zhang, M. et al., PGE2 signaling through the EP4 receptor on fibroblasts upregulates RANKL and stimulates osteolysis. J. Bone Miner. Res. 2009, 24, 1753-1762. 
[6] Briscoe, C. P., Tadayyon, M., Andrews, J. L., Benson, W. G. et al., The orphan $\mathrm{G}$ protein-coupled receptor GPR40 is activated by medium and long chain fatty acids. J. Biol. Chem. 2003, 278, 11303-11311.

[7] Brown, A. J., Goldsworthy, S. M., Barnes, A. A., Eilert, M. M. et al., The orphan $\mathrm{G}$ protein-coupled receptors GPR41 and GPR43 are activated by propionate and other short chain carboxylic acids. J. Biol. Chem. 2003, 278, 11312-11319.

[8] Diascro, D. D., Jr., Vogel, R. L., Johnson, T. E., Witherup, K. M. et al., High fatty acid content in rabbit serum is responsible for the differentiation of osteoblasts into adipocyte-like cells. J. Bone Miner. Res. 1998, 13, 96-106.

[9] Himes, R. W., Smith, C. W., TIr2 is critical for diet-induced metabolic syndrome in a murine model. FASEB J. 2010, 24, 731-739.

[10] Hwang, D., Modulation of the expression of cyclooxygenase2 by fatty acids mediated through toll-like receptor 4-derived signaling pathways. FASEB J. 2001, 15, 2556-2564.

[11] Maurin, A. C., Chavassieux, P. M., Meunier, P. J., Expression of PPARgamma and beta/delta in human primary osteoblastic cells: influence of polyunsaturated fatty acids. Calcif. Tissue Int. 2005, 76, 385-392.

[12] Covington, D. K., Briscoe, C. A., Brown, A. J., Jayawickreme, C. K., The G-protein-coupled receptor 40 family (GPR40GPR43) and its role in nutrient sensing. Biochem. Soc. Trans. 2006, 34, 770-773.

[13] Itoh, Y., Kawamata, Y., Harada, M., Kobayashi, M. et al., Free fatty acids regulate insulin secretion from pancreatic beta cells through GPR40. Nature 2003, 422, 173-176.

[14] Latour, M. G., Alquier, T., Oseid, E., Tremblay, C. et al., GPR40 is necessary but not sufficient for fatty acid stimulation of insulin secretion in vivo. Diabetes 2007, 56, 1087-1094.

[15] Matsumura, S., Mizushige, T., Yoneda, T., Iwanaga, T. et al., GPR expression in the rat taste bud relating to fatty acid sensing. Biomed. Res. 2007, 28, 49-55.

[16] Edfalk, S., Steneberg, P., Edlund, H., Gpr40 is expressed in enteroendocrine cells and mediates free fatty acid stimulation of incretin secretion. Diabetes 2008, 57, 2280-2287.

[17] Ma, D., Zhang, M., Larsen, C. P., Xu, F. et al., DHA promotes the neuronal differentiation of rat neural stem cells transfected with GPR40 gene. Brain Res. 2010, 1330, 1-8.

[18] Yamashima, T., A putative link of PUFA, GPR40 and adultborn hippocampal neurons for memory. Prog. Neurobiol. 2008, 84, 105-115.

[19] Wauquier, F., Philippe, C., Leotoing, L., Mercier, S. et al., The free fatty acid receptor $G$ protein-coupled receptor 40 (GPR40) protects from bone loss through inhibition of osteoclast differentiation. J. Biol. Chem. 2013, 288, 6542-6551.

[20] Philippe, C., Wauquier, F., Lyan, B., Coxam, V. et al., GPR40, a free fatty acid receptor, differentially impacts osteoblast behavior depending on differentiation stage and environment. Mol. Cell. Biochem. 2016, 412, 197-208.

[21] Philippe, C., Wauquier, F., Leotoing, L., Coxam, V. et al., GW9508, a free fatty acid receptor agonist, specifically in- duces cell death in bone resorbing precursor cells through increased oxidative stress from mitochondrial origin. Exp. Cell Res. 2013, 319, 3035-3041.

[22] Monfoulet, L. E., Philippe, C., Mercier, S., Coxam, V. et al., Deficiency of G-protein coupled receptor 40, a lipid-activated receptor, heightens in vitro- and in vivo-induced murine osteoarthritis. Exp. Biol. Med. 2015, 240, 854-866.

[23] Onal, M., Xiong, J., Chen, X., Thostenson, J. D. et al., Receptor activator of nuclear factor kappaB ligand (RANKL) protein expression by B lymphocytes contributes to ovariectomyinduced bone loss. J. Biol. Chem. 2012, 287, 29851-29860.

[24] Seidlova-Wuttke, D., Nguyen, B. T., Wuttke, W., Long-term effects of ovariectomy on osteoporosis and obesity in estrogen-receptor-beta-deleted mice. Comp. Med. 2012, 62, 8-13.

[25] Ludgero-Correia, A., Jr., Aguila, M. B., Mandarim-deLacerda, C. A., Faria, T. S., Effects of high-fat diet on plasma lipids, adiposity, and inflammatory markers in ovariectomized C57BL/6 mice. Nutrition 2012, 28, 316-323.

[26] Xiao, Y., Cui, J., Li, Y. X., Shi, Y. H. et al., Expression of genes associated with bone resorption is increased and bone formation is decreased in mice fed a high-fat diet. Lipids 2010, 45, 345-355.

[27] Zhao, L. J., Liu, Y. J., Liu, P. Y., Hamilton, J. et al., Relationship of obesity with osteoporosis. J. Clin. Endocrinol. Metab. 2007, 92, 1640-1646.

[28] Yamate, T., Mocharla, H., Taguchi, Y., Igietseme, J. U. et al., Osteopontin expression by osteoclast and osteoblast progenitors in the murine bone marrow: demonstration of its requirement for osteoclastogenesis and its increase after ovariectomy. Endocrinology 1997, 138, 3047-3055.

[29] Wauquier, F., Leotoing, L., Coxam, V., Guicheux, J. et al., Oxidative stress in bone remodelling and disease. Trends Mol. Med. 2009, 15, 468-477.

[30] Ota, T., CCR5: a novel player in the adipose tissue inflammation and insulin resistance? Adipocyte 2013, 2, 99-103.

[31] Gao, B., Huang, Q., Jie, Q., Wang, L. et al., Dose-response estrogen promotes osteogenic differentiation via GPR40 (FFAR1) in murine BMMSCs. Biochimie 2015, 110, 36-44.

[32] Oh, D. Y., Talukdar, S., Bae, E. J., Imamura, T. et al., GPR120 is an omega-3 fatty acid receptor mediating potent antiinflammatory and insulin-sensitizing effects. Cell 2010, 142, 687-698.

[33] Cornish, J., MacGibbon, A., Lin, J. M., Watson, M. et al., Modulation of osteoclastogenesis by fatty acids. Endocrinology 2008, 149, 5688-5695.

[34] Ma, W., Wu, J. H., Wang, Q., Lemaitre, R. N. et al., Prospective association of fatty acids in the de novo lipogenesis pathway with risk of type 2 diabetes: the cardiovascular health study. Am. J. Clin. Nutr. 2015, 101, 153-163.

[35] Soto-Vaca, A., Losso, J. N., McDonough, K., Finley, J. W., Differential effect of 14 free fatty acids in the expression of inflammation markers on human arterial coronary cells. J. Agric. Food Chem. 2013, 61, 10074-10079. 